\title{
The peridotite deformation cycle and the deep impact of subduction beneath the Wyoming Craton
}

\author{
EMILY CHIN ${ }^{1}$, BENJAMIN CHILSON-PARKS ${ }^{2}$, YUVAL \\ BONEH $^{3}$, GREG HIRTH ${ }^{4}$, ALBERTO SAAL ${ }^{4}$, B. CARTER \\ HEARN $^{5}$ AND ERIK H. HAURI ${ }^{6}$ \\ ${ }^{1}$ Scripps Institution of Oceanography UC San Diego \\ ${ }^{2}$ University of Connecticut \\ ${ }^{3}$ Ben-Gurion University of the Negev \\ ${ }^{4}$ Brown University \\ ${ }^{5}$ USGS \\ ${ }^{6}$ Carnegie Institution for Science \\ Presenting Author: e8chin@ucsd.edu
}

Cratons are commonly thought to defy tectonic breakup over their billion year lifespans, but a few cratons, such as North China and Wyoming, appear to have been disrupted by subduction. Here, we examine Eocene, kimberlite-hosted garnet peridotite xenoliths from the edge vs. the interior of the Wyoming Craton. Using a number of internally consistent EBSD datasets, we show that discrepancies between bulk rock fabric (CPO) and grain substructures (misorientations and subgrain boundary orientations) indicate complex, non-simple shear deformation kinematics. We combine EBSD data with water contents in nominally anhydrous minerals (olivine, orthopyroxene, clinopyroxene, garnet) analyzed by ion microprobe and REE mineral chemistries by laser ablation ICPMS. Our results show that the Wyoming Craton experienced a craton-scale deformation and metasomatism cycle that affected the interior vs. edge differently. Interior cratonic mantle show extreme sinusoidal garnet REE patterns and elevated water contents, and in spite of their protogranular textures, also exhibit strong, B-type olivine fabric, which is associated with hydrous deformation. We propose that the Cenozoic Laramide Orogeny was the cause of these features. By contrast, edge cratonic mantle show normal garnet REE patterns and low water content, and their porphyroclastic and transitional textures correlate with Atype fabric. The distinctive presence of annealed olivine tablets from edge xenoliths points to rapid annealing at high homologous T's following a high-strain deformation event. We propose that the edge xenoliths reflect disturbance at the edge of the Wyoming Craton associated with Eocene slab rollback, which initiated a Rayleigh-Taylor style drip deforming under complex strain geometries. Such a drip may be similar to the anisotropy vortex or "Great Drip" seismically observed beneath the Nevada Great Basin today. Collectively, our data show that cratonic lithosphere may experience a deformation cycle initiated by flat slab subduction, punctuated by rapid deformation that eventually led to lithospheric instability. 